\title{
Stability Is Important to Clinicians When Selecting a Botulinum Toxin Product
}

\author{
Seung Min Oh, MD, MMBA ${ }^{1}$ \\ Bong Cheol Kim, MD² \\ Min Ho Lee, $M^{3}$ \\ Dong Wook Shin, MD, DrPH ${ }^{4}$ \\ ${ }^{1}$ ON Clinic, Seoul, Korea \\ ${ }^{2}$ Isu Lamar Clinic, Seoul, Korea \\ ${ }^{3}$ BESTOP Clinic, Suwon, Korea \\ ${ }^{4}$ Department of Family Medicine, Samsung \\ Medical Center, Sungkyunkwan University School \\ of Medicine, Seoul, Korea
}

Received October 13, 2020

Accepted October 23, 2020

\footnotetext{
Correspondence

Dong Wook Shin

Department of Family Medicine, Samsung Medical Center, Sungkyunkwan University School of Medicine, Seoul 06351, Korea

E-mail: dwshin.md@gmail.com

https://orcid.org/0000-0001-8128-8920

(C) Korean Society for Laser, Dermatology and Trichology

(c) This is an open access article distributed under the terms of the Creative Commons Attribution NonCommercial License (http://creativecommons.org/ licenses/by-nc/4.0) which permits unrestricted noncommercial use, distribution, and reproduction in any medium, provided the original work is properly cited.
}

\section{Background and Objectives}

The use of botulinum toxin injections in cosmetic procedures is widely practiced in aesthetic medicine. Recently, various toxin products have been developed and are appearing in the medical market. We sought to document what clinicians consider important when selecting a toxin product, excluding price, which was found to be the most important factor in our previous study.

\section{Materials and Methods}

At the conference of the Korean Association for Laser, Dermatology, and Trichology (KALDAT) held on July 26, 2020, we conducted a web-based realtime survey to investigate the bases for clinicians' decisions on botulinum toxin products, particularly what clinicians consider most important when selecting toxin products. In addition, we examined whether the purpose of the procedure affected their choices.

\section{Resullts}

When clinicians chose a botulinum toxin product, the second most important factor after price was the stability of the toxin. This was the same for procedures to improve wrinkles and to reduce muscle volume.

\section{Conclusion}

The stability of toxin products is an essential aspect to achieving consistent and predictable results, and as such, clinicians consider it very important when selecting toxin products. Companies that are producing or preparing to develop botulinum toxin products should pay attention to securing and maintaining product stability.

\section{Key words}

Botulinum toxin, Stability, Selection 


\section{AESTHETICS}

\section{INTRODUCTION}

Botulinum toxin injections are some of the most frequently performed procedures in cosmetic medicine [1]. In the early 2000s, only three to four botulinum toxins were licensed for use worldwide; however, more than 10 botulinum toxins are currently in use or are being prepared for approval. Of these, four are produced in Korea, and an another five are awaiting KFDA approval [2]. As the variety of toxin products has diversified, so has their range of use, and cases of the use of toxins in large amount capacity are increasing $[3,4]$. Toxin products, however, are not identical or interchangeable, varying in molecular structure and other aspects $[5,6]$. Accordingly, identifying on which criteria clinicians base their selection of a botulinum toxin product will help us gauge which products will likely garner the greatest interest and survive the medical market.

Two years ago, we conducted a survey to determine what factors clinicians consider the most important when choosing a botulinum toxin product. Clinicians replied that price was the most important consideration in choosing a toxin product. Additionally, when asked what concerns them the most while using botulinum toxin, they responded that tolerance to toxins was their greatest concern [7]. Nevertheless, as various products continue to be added to the market, it is necessary to know what clinicians consider important in addition to price.

Therefore, in this study, we conducted administered survey to clinicians who are actively performing botulinum toxin treatments at a hospital to determine, excluding price, the criteria on which they base their decisions to use a particular toxin.

\section{MATERIALS AND METHODS}

\section{Data collection}

This study was conducted at the 34th Spring Conference of the Korean Association for Laser, Dermatology, and Trichology (KALDAT) held at the InterContinental Hotel Parnas Tower in Samseong-dong, Seoul on July 26, 2020. The Korean Center for Disease Control's quarantine guidelines due to COVID-19 outbreak were followed, and the questionnaire was administered to clinicians attending the conference via the internet in real time on a mobile basis. Participating doctors were allowed to enter the conference only if they passed the quarantine inspection questionnaire and body temperature test. The conference secretariat sent a text message containing a link to clinicians who were approved for admission to the conference. Clinicians participated in web surveys by clicking the link in the text message sent to their mobile phone at their own discretion. Since the link in the text message contained an encrypted, unique number for each individual, the survey participants could only participate in the survey once. Duplicate participation by others was not possible: even if someone copied the same link and accessed it through their mobile phone, they could not participate in the survey. All data were encrypted, and personal identification was impossible. By accessing the web survey page (Fig. 1), participants could read the consent form for the use of personal information, agree to the use thereof and then participate in the survey. Data were collected only when the final question in the survey was completed and the "Finish" button was pressed.

This web-based, real-time mobile survey method has been utilized at KALDAT academic conferences since 2018 , and this study is the fourth use thereof. The method is based on the long polling technology of the ajax library, a JavaScript language commonly used in chat solutions, called jQuery. Through this, the web page manager is able to check the results of the surveyors via a real-time graph without the need to refresh the page.

\section{Measurement}

The survey consisted of 13 multiple-choice questions, including questions on sex, age, and specialization. The multiple-choice questionnaire allowed only one answer to be selected and was design to collect information on the survey participant's experience with injection procedures (How long have you performed botulinum toxin treatments?), purposes of the procedures (At what ratio do you perform botulinum toxin treatments to remove wrinkles compared

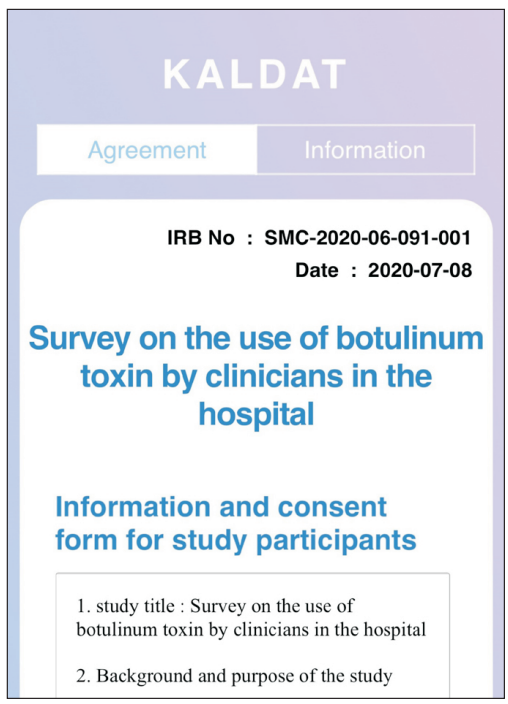

Fig. 1. Web survey page. 
to those to reduce muscle size?), the product selection criteria for individual procedures (For the purpose of removing wrinkles, what is the most important selection criteria for a toxin product other than its price?), and awareness of differences in individual products (Do you think there is a difference in product stability [=constant potency] when using the amount of botulinum toxin equivalent to the equivalent potency for individual products?).

\section{Statistical analysis}

The frequency of responses to each question was analyzed. For analysis, participants were divided into groups aged under 39 or over the age of 40 years and into an aesthetic group (aesthetic physicians, dermatologists, plastic surgeons) and others group. An aesthetic physician refers to a clinician who focuses more on cosmetic procedures than general disease treatment. Others refer to medical staff who primarily treat general diseases, but also perform some cosmetic procedures. Differences in responses between groups were analyzed by Pearson's chi-squared test, and $p$-values $<0.05$ were considered statistically significant. All statistical analyses were performed using Stata version 15.0 (Stata Corp., College Station, TX, USA).

\section{Ethics}

This study was approved by the Institutional Review Board of Samsung Medical Center (SMC-2020-06-091-001).

\section{RESULTS}

\section{Characteristics of the survey participants}

A total of 105 people participated in the survey. The demographic and sociological characteristics of the clinicians who participated in the survey, as well as their experience with injection procedures, are listed in Table 1. The average age of the survey participants was 40.9 years (standard deviation, 9.1 years), and $36.2 \%$ were female. Aesthetic physicians comprised two-thirds of all respondents. Around half of the participants had more than 5 years of experience with aesthetic procedures. Procedure volumes varied, with survey participants performing $2-5$ cases (28.6\% of respondents), 6-10 (22.9\%), and 11-30 (21.9\%) per day.

\section{Practice patterns according to physician group}

Among the younger physicians, procedures to reduce muscle size were more frequently performed, and the difference therein between age groups was statistically significant (>50\% of all procedures, $38.0 \%$ vs. $18.2 \%)(p=0.013)$. The frequency of procedures performed to reduce muscle size was also greater in the aesthetic group than the others group (> $50 \%$ of all procedures, 29.5 vs. $22.2 \%$ ); this difference was also statistically significant $(p=0.002)$ (Table 2 ).

Table 1. The demographic and sociological characteristics of the clinicians who participated in the survey

\begin{tabular}{|c|c|c|}
\hline Question & Answer & $\mathrm{N}(\%)$ \\
\hline Age, mean (SD) & \multicolumn{2}{|c|}{$40.9(9.1)^{*}$} \\
\hline \multirow[t]{2}{*}{ Sex } & Male & $67(63.8)$ \\
\hline & Female & $38(36.2)$ \\
\hline \multirow[t]{4}{*}{ Specialty } & Aesthetic physician $^{\dagger}$ & $69(65.7)$ \\
\hline & Dermatologist & $5(4.8)$ \\
\hline & Plastic surgeon & $4(3.8)$ \\
\hline & Others $^{\ddagger}$ & $27(25.7)$ \\
\hline \multirow{5}{*}{$\begin{array}{l}\text { Experience with aesthetic } \\
\text { procedures }\end{array}$} & $<1 \mathrm{mo}$ & $13(12.4)$ \\
\hline & $1 \mathrm{mo}<<1 \mathrm{Yr}$ & $12(11.4)$ \\
\hline & 1-3 Yrs & 22 (20.9) \\
\hline & 3-5 Yrs & $9(8.6)$ \\
\hline & 5 Yrs $<$ & $49(46.7)$ \\
\hline \multirow[t]{5}{*}{ Procedure volume } & $<1$ case/day & $14(13.3)$ \\
\hline & $2-5$ cases/day & $30(28.6)$ \\
\hline & $6-10$ cases/day & $24(22.9)$ \\
\hline & $11-30$ cases/day & 23 (21.9) \\
\hline & 31 cases/day < & 14 (13.3) \\
\hline
\end{tabular}

* Means (standard deviation). ${ }^{\dagger}$ Clinicians who primarily perform cosmetic procedures. ${ }^{\ddagger} \mathrm{Clinicians}$ who focus on general disease treatment, but also perform some cosmetic procedures.

Table 2. Practice patterns according to physician age and specialty

\begin{tabular}{|c|c|c|c|c|c|}
\hline \multirow{2}{*}{ Answer } & \multirow{2}{*}{ All } & \multicolumn{2}{|c|}{ By age } & \multicolumn{2}{|c|}{ By specialty } \\
\hline & & $<40$ & $>40$ & Aesthetic & Others \\
\hline Total number & $105(100)$ & $50(100)$ & $55(100)$ & $78(100)$ & $27(100)$ \\
\hline Wrinkle removing procedure over $80 \%$ & $29(27.6)$ & $7(14)$ & $22(40)$ & $14(17.9)$ & $15(55.6)$ \\
\hline Wrinkle removing 50-80\% \& Muscle reduction $20-50 \%$ & $47(44.8)$ & $24(48)$ & $23(41.8)$ & $41(52.6)$ & $6(22.2)$ \\
\hline Wrinkle removing $20-50 \%$ \& Muscle reduction $50-80 \%$ & $28(26.7)$ & $18(36)$ & $10(18.2)$ & $22(28.2)$ & $6(22.2)$ \\
\hline Muscle reduction over $80 \%$ & $1(1)$ & $1(2)$ & $0(0)$ & $1(1.3)$ & $0(0)$ \\
\hline $\mathrm{p}$-value & & & 0.013 & & 0.002 \\
\hline
\end{tabular}




\section{Toxin selection criteria according to treatment type}

More than half $(53.3 \%)$ of the clinicians responded that, excluding price, the stability of toxins was the most important criterion for selecting a botulinum toxin product for wrinkle improvement, followed by safety $(20.0 \%)$ and the duration of effects (14.3). This was not significantly different by age group ( $p=0.333$ ) or specialty group ( $p=0.780$ ). Stability was also the most important selection criterion for muscle size reduction procedures, followed by a stronger ef- fect $(15.2 \%)$, safety $(14.3 \%)$, reduced tolerance $(12.4 \%)$, and duration of effects $(10.5 \%)$. While this did not significantly differ between the age $(p=0.098)$ or specialty groups $(p=$ 0.058 ), compared to their counterparts, younger and aesthetic physicians tended to consider that tolerance (22.0 vs. $3.6 \%$ and 16.7 vs. $0 \%$ ) and stronger effects (18.0 vs. $12.7 \%$ and 17.9 vs. $7.4 \%$ ) held greater importance (Table 3 ).

Table 3. Toxin selection criteria according to treatment type



Table 4. Perceived differences between products among clinicians

\begin{tabular}{|c|c|c|c|c|c|c|}
\hline \multirow{2}{*}{ Question } & \multirow{2}{*}{ Answer } & \multirow{2}{*}{ Result } & \multicolumn{2}{|c|}{ By age } & \multicolumn{2}{|c|}{ By physician type } \\
\hline & & & $<40$ & $>40$ & Aesthetic & Others \\
\hline \multirow[t]{5}{*}{ Difference in stability between products } & Very different & $8(7.6)$ & $4(8)$ & $4(7.8)$ & $6(7.7)$ & $2(7.4)$ \\
\hline & Slightly different & $57(54.2)$ & $25(50)$ & $32(58.2)$ & $41(52.6)$ & $16(59.3)$ \\
\hline & Average & $25(23.8)$ & $15(30)$ & $10(18.2)$ & $22(28.2)$ & 3 (11.1) \\
\hline & No difference & $0(0)$ & $0(0)$ & $0(0)$ & $0(0)$ & $0(0)$ \\
\hline & Total & $105(100)$ & $50(100)$ & $55(100)$ & $78(100)$ & $27(100)$ \\
\hline \multirow[t]{5}{*}{ Difference in duration between products } & Very different & $8(7.6)$ & $4(8)$ & $4(7.8)$ & $5(6.4)$ & 3 (11.1) \\
\hline & Slightly different & $53(50.5)$ & $22(44)$ & $31(56.4)$ & $36(46.2)$ & $17(63.0))$ \\
\hline & Average & $28(26.7)$ & $18(36)$ & $10(18.2)$ & $24(30.8)$ & $4(14.8)$ \\
\hline & No difference & $0(0)$ & $0(0)$ & $0(0)$ & $0(0)$ & $0(0)$ \\
\hline & Total & 105 (100) & $50(100)$ & 55 (100) & $78(100)$ & 27 (100) \\
\hline
\end{tabular}




\section{Perceived differences between products}

The survey participants were asked whether there is a difference in the stability of individual toxin products. Overall, 7.61\% (8/105) responded that there are marked differences in product stability, while 54.3\% (57/105) indicated that there are only slight differences. Also, $56.2 \%$ of the participants stated that they felt that there was a difference in the durations of effects for each toxin product (very different, 7.6\%; slightly different, 48.6\%) (Table 4).

\section{DISCUSSION}

In this study, we sought to determine what criteria clinicians use to decide on a toxin product for use in botulinum toxin treatments, other than price. We found that clinicians more often than not based their decision on the stability of the product.

Botulinum toxin is a powerful neuromuscular paralysis toxin, and its dose equivalent to LD 50 is very small. Since excessive administration can cause fatal side effects, such as respiratory distress [8], it is necessary to inject an appropriate dose. To this end, the ability of a production company to make a product that has a stable and consistent concentration across its product line is important. Interestingly, however, $62 \%$ of the survey respondents included in this study reported perceiving a noticeable difference in the stabilities of individual products. This is meaningful not only to companies that have developed and commercialized toxins, but also to companies that want to develop toxins in the future. Although stability must be confirmed in the process of obtaining marketing approval, this results shows that continuous quality control is important after sales start.

Of note, we found that younger physicians and those specializing in cosmetic procedures performed more botulinum toxin treatments to reduce muscle size than their counterparts. This result, although not statistically significant, was associated with greater concerns for tolerance and stronger effects when choosing a toxin product. Muscle size reduction procedures generally require a higher dose of toxin than wrinkle improvement procedures, and as such, concerns for overdosing and tolerance are relatively high. Also, many muscle size reduction procedures fall under offlabel uses (i.e., procedures not approved for botulinum toxin use), which we suspect younger and aesthetic physicians may be more willing to apply. The approved indications for which Allergan's Botox ${ }^{\circledR}$ is licensed in Korea are glabellar lines, hyperhidrosis, crow's feet, blepharospasm, strabismus, migraine, neck muscle tension disorders, apical deformities, upper limb muscle stiffness, overactive bladder, and urinary incontinence [9]. Hugel's Botulex ${ }^{\circledR}$ has been approved for treating glabellar wrinkles, crow's feet blepharospasm, and apical deformity upper limb muscle stiffness. Medytox's Meditoxin ${ }^{\circledR}$ has been approved for use in treating [10] glabellar wrinkles, crow's feet wrinkles, blepharospasm, dystonia, apical deformities, and upper extremity muscle stiffness [11]. Accordingly, most of the areas that are treated for the purpose of reducing muscle size (deltoid muscles, calf muscles, quadriceps femoris, trapezius muscles, etc.) are mostly off-labeled use.

In regards to tolerance in particular, a total of six of the 105 respondents reported considering tolerance as the first criterion for product selection when performing a procedure for wrinkle improvement. On the other hand, when performing a procedure for the purpose of reducing muscle size, thirteen respondents said that tolerance ought to be considered first when selecting a toxin product. The latter 13 respondents were all aesthetic physicians specializing in performing cosmetic procedures, and thus, they likely more often use relatively high doses of botulinum toxin in procedures aimed at reducing muscle size.

\section{CONCLUSION}

In clinical practice, physicians performing botulinum toxin treatments find the stability of toxin products to be the most important product selection criterion other than price, and differences in stability between individual products appear to be a shared concern. Altogether, our results emphasize the desires of clinicians for stable toxin products and suggest that manufacturers would garner greater interest in their products if they show consistent and stable titers of toxin.

\section{ACKNOWLEDGEMENTS}

We would like to thank the members of KALDAT who helped us conduct this survey. We would also like to thank Beom Jin Shin, CEO and Dong Hyun Kim, Programmer of MADEINREAL Company who developed the real-time, webbased mobile survey platform.

\section{CONFLICT OF INTEREST}

No potential conflict of interest relevant to this article was reported.

\section{REFERENCES}

1. Zarringam D, Decates T, Slijper HP, Velthuis P. Increased usage of botulinum toxin and hyaluronic acid fillers in young 


\section{AESTHETICS}

adults. J Eur Acad Dermatol Venereol 2020;34:e602-4.

2. Field $M$, Splevins $A$, Picaut $P$, van der Schans $M$, Langenberg J, Noort D, et al. AbobotulinumtoxinA (Dysport ${ }^{\circledR}$ ), OnabotulinumtoxinA (Botox ${ }^{\circledR}$ ), and IncobotulinumtoxinA (Xeomin ${ }^{\circledR}$ ) neurotoxin content and potential implications for duration of response in patients. Toxins (Basel) 2018;10:535.

3. Zhou RR, Wu HL, Zhang XD, Ye LL, Shao HJ, Song XH, et al. Efficacy and safety of botulinum toxin type $A$ injection in patients with bilateral trapezius hypertrophy. Aesthetic Plast Surg 2018;42:1664-71.

4. Shi W, Zhu L, Wang T, Zhang G, Lian J. Classification of hypertrophic gastrocnemius muscle and its treatment with botulinum toxin A. Aesthetic Plast Surg 2019;43:1588-94.

5. Walker TJ, Dayan SH. Comparison and overview of currently available neurotoxins. J Clin Aesthet Dermatol 2014;7:31-9.

6. Brin MF, James C, Maltman J. Botulinum toxin type A products are not interchangeable: a review of the evidence. Biologics 2014;8:227-41.
7. Oh SM, Lee CW, Lee SI, Kim BC. Analysis of side effects from cosmetic procedures with botulinum toxin. Aesthet 2020;1:17-21.

8. Coban A, Matur Z, Hanagasi HA, Parman Y. latrogenic botulism after botulinum toxin type $A$ injections. Clin Neuropharmacol 2010;33:158-60.

9. Ministry of Food and Drug Safety. Efficacy and effect [online]. [cited 2020 Jun 20]. Available from: https://nedrug.mfds. go.kr/pbp/cmn/pdf/drb/200901660/EE

10. Ministry of Food and Drug Safety. Medication detail information: Botulax ${ }^{\circledR}$ [online]. [cited 2020 Jun 20]. Available from: https://nedrug.mfds.go.kr/pbp/ССВВВ01/ get/temDetail?itemSeq=200901953

11. Ministry of Food and Drug Safety. Medication detail information: Meditoxin ${ }^{\circledR}$ [online]. [cited 2020 Jun 20]. Available from: https://nedrug.mfds.go.kr/pbp/ССВBВ01/ getltemDetail?itemSeq $=200902348$ 